\title{
Relation of Structure, Composition and Glass Forming Ability in Zr-Cu Binary Amorphous Alloys
}

\author{
DANG Yizong ${ }^{1, \mathrm{a}}$, WANG $\mathrm{Lu}^{2, \mathrm{~b}}$ and FAN Qunbo ${ }^{2, \mathrm{c}}$ \\ ${ }^{1}$ School of Materials Science and Engineering, Beihang University, Beijing 100191, PR China \\ ${ }^{2}$ School of Materials Science and Engineering, Beijing Institute of Technology, Beijing 100081, PR \\ China \\ adangyizong@163.com¹, ${ }^{b}$ wanglu@bit.edu.cn, ${ }^{\mathrm{c}}$ fanqunbo@bit.edu.cn
}

\begin{abstract}
Molecular dynamics simulation was used to simulate $\mathrm{Zr}-\mathrm{Cu}$ binary system, in which the relationship between structure, composition and glass forming ability was study. Atomic local structures were analyzed from view of chemical and topological short range order. Reduction fraction of full icosahedra $\left(B_{\mathrm{c}}\right)$ was developed to establish the relation of structure-composition and glass forming ability(GFA) in $\mathrm{Zr}-\mathrm{Cu}$ binary system. Obviously peaks were observed at some certain compositions which own the good GFA. As a structure factor, $B_{\mathrm{c}}$ could be a indicator of GFA of $\mathrm{Zr}-\mathrm{Cu}$ alloys. Our works contributed to further understanding the effect of atomic structures on glass forming.
\end{abstract}

\section{Introduction}

Bulk metallic glasses (MGs) was paid much attention due to their unique properties, such as high strength, high elastic strain limit, and high corrosion resistance ${ }^{[1,2,3]}$. It was a throughout central issues to build the relationship between structure and properties in material science field, because properties of materials were determined by atomic structure ${ }^{[4,5]}$. However, up to now, detailed micro-structural information was very lack for metallic glasses. It was still a mystery that a small change in composition could lead to sharply change of glass-forming ability (GFA). So, building composition-structure-GFA relationship was very important to study GFA.

Recently, many owning good glasses-forming composition in $\mathrm{Zr}-\mathrm{Cu}$ binary system were found ${ }^{[6,7]}$. As a binary alloy system, it was a simple and ideal model system for studying the correlation between atomic structure, composition and GFA. Full Icosahedra(F-ICO) as a short-range order had been found in a lot of amorphous alloys. F-ICO clusters were observed not only in $\mathrm{Zr}-\mathrm{Cu}$ binary amorphous alloy, but also in high temperature melt by ab initio molecular dynamics(MD ${ }^{[8,9,10]}$. In previous works, F-ICO increased the viscosity of the liquids and contributed to an enhance $\mathrm{GFA}^{[11,12]}$, whereas other types of polyhedral could not show the property. In present work, topologic and chemical structure change with composition were study extensively. A parameter based on the relative change is introduced

Corresponding author:dangyizong@163.com 
to build the relationship between structure and GFA.

\section{Simulation Method}

In the letter, authors performed MD simulations with Tight bonding (TB)potential to explore the effect of the short range ordering structure on GFA for $\mathrm{Zr}$-Cu binary system. The simulation process was in the NTP(constant number of particles-pressure-temperature) ensemble using the Material Explorers software. The MD simulation was carried out in a super cell including 20000 atoms under the periodic boundary conditions. To build different composition alloy models, the appropriate amount of copper atom and zirconium atom were randomly distributed in the initial B2 structure. These alloy models were first equilibrated at $T=2000 \mathrm{~K}$. After equilibrating the structure in the liquid phase, these models were quenched to rooming temperature $(300 \mathrm{~K})$ using the conjugated gradient method. The cooling rate was $2 \mathrm{~K} . \mathrm{ps}^{-1}$ at zero external pressure. A time step of $2 \mathrm{ps}$ was used. The resulting atomic structures were further optimized using the conjugated gradient method.

\section{Result and Discussion}

Voronoi tessellation technique analyses were used to investigate the atoms' nearest-neighbor environment evolution with composition. The different coordination polyhedral surrounding a central atom could be characterized by the Voronoi index $<n_{3}, n_{4}, n_{5}, n_{6}, \ldots>$, where $n_{\mathrm{i}}$ denoted the number of $\mathrm{i}$-edged faces of the polyhedron. Based on this, Voronoi tessellation technique was usually applied to analyze topological short range order(TSRO) structure of amorphous state. F-ICO clusters (Voronoi index $<0,0,12,0\rangle$ ) was the most stable and dense structure in various types of TSRO structures. F-ICO clusters made dynamic of metallic glasses slowed down and increased stability of alloy melt, which benefited GFA in $\mathrm{Zr}-\mathrm{Cu}$ system $^{[11]}$. So, the F-ICO cluster was usually used as the key indicator of stability of the glass structure. Moreover, it was worth notice that F-ICO clusters were almost $\mathrm{Cu}$ centered in $\mathrm{Zr}-\mathrm{Cu}$ binary system in our works. It was consistent with the experimental measurement and MD simulations.

The evolution of the fraction of F-ICO clusters $\left(f_{\mathrm{F}-\mathrm{ICO}}\right)$ in $\mathrm{Zr}-\mathrm{Cu}$ alloy as function of temperature (during the quenching process) was obtained, as shown in Fig.1. It was observed that the $f_{\text {F-ICO }}$ value sharply increased as the temperature drop in over composition alloys. The results were in agreement with previous works. Authors evaluated the correlation between $\mathrm{Cu}$ content and $f_{\mathrm{F}-\mathrm{ICO}}$ at rooming temperature. It was found that the $\mathrm{Cu}$-rich $(\mathrm{Cu}$ content more than equal to $50 \%$ )systems contained more F-ICO clusters.

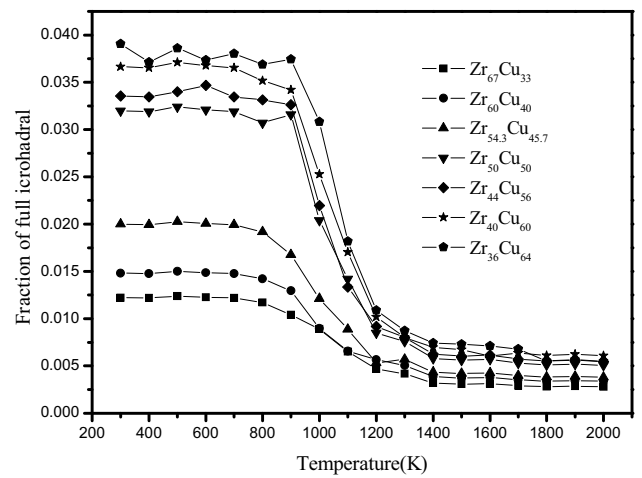

Fig.1 Temperature evolution of the fraction of F-ICO clusters during quenching process in $\mathrm{Zr}-\mathrm{Cu}$ alloys. 
The $f_{\mathrm{F}-\mathrm{ICO}}$ Values over the seven compositional ranges, from $\mathrm{Zr}_{67} \mathrm{Cu}_{33}$ to $\mathrm{Zr}_{64} \mathrm{Cu}_{36}$, from $\mathrm{Zr}_{61} \mathrm{Cu}_{39}$ to $\mathrm{Zr}_{59} \mathrm{Cu}_{41}$, from $\mathrm{Zr}_{56} \mathrm{Cu}_{44}$ to $\mathrm{Zr}_{54} \mathrm{Cu}_{46}$, from $\mathrm{Zr}_{51.5} \mathrm{Cu}_{48.5}$ to $\mathrm{Zr}_{48.5} \mathrm{Cu}_{51.5}$, from $\mathrm{Zr}_{45} \mathrm{Cu}_{55}$ to $\mathrm{Zr}_{43} \mathrm{Cu}_{57}$, from $\mathrm{Zr}_{41.5} \mathrm{Cu}_{58.5}$ to $\mathrm{Zr}_{39} \mathrm{Cu}_{61}$, from $\mathrm{Zr}_{37} \mathrm{Cu}_{63}$ to $\mathrm{Zr}_{35} \mathrm{Cu}_{65}$, were shown in Fig.2, in which the trend exhibited increase with $\mathrm{Cu}$ content. As $\mathrm{Cu}$ content increased, the $f_{\text {F-ICO }}$ Value increased quickly and connected with each other. These configurations slowed down the dynamics in $\mathrm{Zr}-\mathrm{Cu}$ system. Based on the above description, $\mathrm{Cu}$ content was the more higher and the more stronger of GFA . In fact, $\mathrm{Cu}$ content did not forming direct ratio to GFA in $\mathrm{Zr}-\mathrm{Cu}$ system. For example, it was well know that the tow best glass formers were $\mathrm{Zr}_{50} \mathrm{Cu}_{50}{ }^{[10,13]}$ and $\mathrm{Zr}_{35.5} \mathrm{Cu}_{64.5}{ }^{[9]}$, at which $2 \mathrm{~mm}$ rods could be cast completely metallic glasses, in $\mathrm{Zr}-\mathrm{Cu}$ systems, according to previously reported experimental and simulations result. However, the $f_{\text {F-ICO }}$ values for $\mathrm{Zr}_{50} \mathrm{Cu}_{50}$ and $\mathrm{Zr}_{35.5} \mathrm{Cu}_{64.5}$ were not the highest. The $f_{\mathrm{F}-\mathrm{ICO}}$ value of $\mathrm{Zr}_{50} \mathrm{Cu}_{50}$ was particularly far lower than the other $\mathrm{Cu}$-rich alloys. So, the $f_{\text {F-ICO }}$ value could not comprehensively characterize the GFA of $\mathrm{Zr}-\mathrm{Cu}$ alloys. However, increasing trend was not linear. The average gradient in every compositional range was obviously different. Meanwhile, it was suggested that $\mathrm{Cu}$ content was not the unique factor on the forming F-ICO cluster. The promoting effect of $\mathrm{Cu}$ content on F-ICO nucleation was different over compositional range.

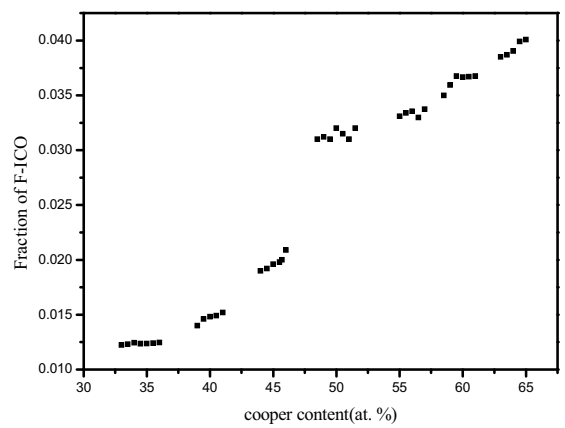

Fig.2 The fraction of F-ICO over the entire range.

In the above composition ranges, the average ratio of $\mathrm{Cu}$ to $\mathrm{Zr}$ in the nearest shell of every atom was calculated. The curve of coordination number $(\mathrm{CN})$ with $\mathrm{Cu}$ content was shown in Fig.3. One might note from Fig.3 that the average $\mathrm{CN}$ of $\mathrm{Cu}$-centered and $\mathrm{Zr}$-centered clusters were from $\mathrm{Cu}_{5.8} \mathrm{Zr}_{7.5}$ to $\mathrm{Cu}_{8.34} \mathrm{Zr}_{5.46}$ and from $\mathrm{Cu}_{6.8} \mathrm{Zr}_{8.5}$ to $\mathrm{Cu}_{10.59} \mathrm{Zr}_{4.9}$, respectively, with $\mathrm{Cu}$-content increased in $\mathrm{Cu}$-rich alloys. The major crystalline phase was $\mathrm{Cu}_{10} \mathrm{Zr}_{7}$ for $\mathrm{Cu}$-rich composition in former works ${ }^{[14]}$. It was shown that the average local chemical environment of atoms closed to $\mathrm{Cu}_{10} \mathrm{Zr}_{7}$. It was also implied that more and more atomic clusters having similar structure with $\mathrm{Cu}_{10} \mathrm{Zr}_{7}$ would be observed in $\mathrm{Cu}$-rich alloys. The major crystalline phase was $\mathrm{Zr}_{2} \mathrm{Cu}$ in $\mathrm{Zr}$-rich composition $(\mathrm{Zr} \text { content less than } 50 \%)^{[14]}$. It was known from Fig. 3 that the average $\mathrm{CN}$ of $\mathrm{Cu}$-centered and $\mathrm{Zr}$-centered clusters were from $\mathrm{Cu}_{5.8} \mathrm{Zr}_{7.5}$ to $\mathrm{Cu}_{3.69} \mathrm{Zr}_{9.38}$ and from $\mathrm{Cu}_{6.8} \mathrm{Zr}_{8.5}$ to $\mathrm{Cu}_{4.6} \mathrm{Zr}_{10.337}$, respectively, with $\mathrm{Zr}$-content increase in $\mathrm{Zr}$-rich alloys. It was also known that the local chemical environment of atoms closed to $\mathrm{Zr}_{2} \mathrm{Cu}$ with $\mathrm{Zr}$ content increase. This was also promoted crystal nucleation rate. To sum up the above arguments, the chemical short range ordering(CSRO) was very sensitive to chemical composition. The evolution of CSRO shortened the atoms' crystallization diffusion distance, and restrained nucleation of F-ICO. 


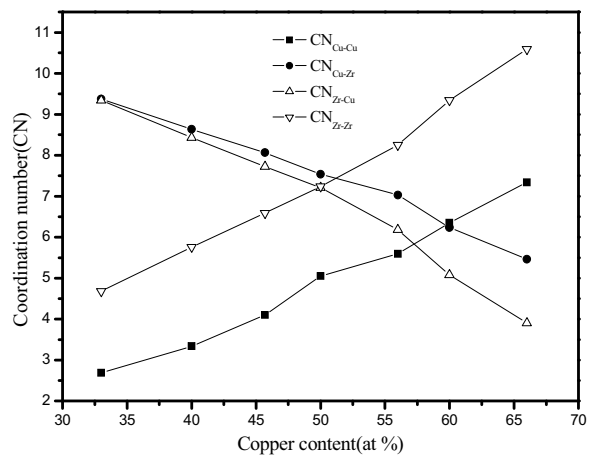

Fig. 3 Total and partial $\mathrm{CN}$ for the molten $\mathrm{Cu}-\mathrm{Zr}$ alloys as a function of concentration at rooming temperature.

On the basis of the above statistical analysis and discussion, a new parameter, $B_{c}$, was developed to establish the relationship between the atomic structure and GFA for $\mathrm{Zr}-\mathrm{Cu}$ binary alloys. $B_{c}$ could be expressed as $B_{c}=f_{\mathrm{F}-\mathrm{ICO}} / 1-f_{\mathrm{Zr}}=f_{\mathrm{F}-\mathrm{ICO}} / f_{\mathrm{Cu}}$, where $f_{\mathrm{F}-\mathrm{ICO}}$ was the fraction of F-ICO clusters and $f_{\mathrm{Cu}}, f_{\mathrm{Zr}}$ were $\mathrm{Cu}$ and $\mathrm{Zr}$ mol content, respectively. $B_{\mathrm{c}}$ was named as "reduction fraction of F-ICO" by authors. The higher $B_{\mathrm{c}}$ value represented that the composition contributed more to form F-ICO clusters and restrained more crystal nucleation as well as stronger GFA.

The curve of $B_{\mathrm{c}}$ of $\mathrm{Zr}-\mathrm{Cu}$ binary alloy was as shown in Fig.4. $B_{\mathrm{c}}$ was still lower in Zr-rich alloy. It was indicated that the alloy composition not only inhibit the F-ICO cluster forming but benefit the crystal nucleation with $\mathrm{Zr}$ increase in $\mathrm{Zr}$-rich content alloy. On the contrary, $B_{\mathrm{c}}$ value in $\mathrm{Cu}$-rich alloy was larger than that in $\mathrm{Zr}$-rich alloy. It was implied that the copper atom in $\mathrm{Cu}$-rich alloy was more easily form F-ICO cluster than that in $\mathrm{Zr}$-rich alloy. Meanwhile, tow peaks at $\mathrm{Zr}_{50} \mathrm{Cu}_{50}$ and $\mathrm{Zr}_{36} \mathrm{Cu}_{64}$ were observed as shown in Fig.4(marked by arrows). Furthermore, the good GFA was also reported in $\mathrm{Zr}_{40} \mathrm{Cu}_{60} .1 .5 \mathrm{~mm}$ rods could be cast completely amorphous ${ }^{[11]}$ in $\mathrm{Zr}_{40} \mathrm{Cu}_{60}$. It was also reflected by $B_{\mathrm{c}}$ value as shown in Fig.4. So, the good match between peak of $B_{\mathrm{c}}$ and GFA indicated that $B_{\mathrm{c}}$ was a fundamental structure factor in determining the ease of glass forming.

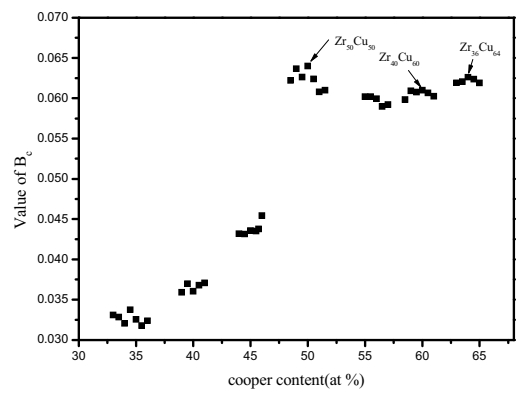

Fig. $4 B_{\mathrm{c}}$ over the entire range.

\section{Conclusion}

In conclusion, to study the compositional dependence of the GFA for $\mathrm{Zr}-\mathrm{Cu}$ binary alloys by molecular dynamics. A large number of specimens with vary initial structure were simulated. Voronoi tessellation method was applied to analyze atomic local topological structures. It could be assumed that the composition acted positive and negative roles to glass forming of $\mathrm{Zr}-\mathrm{Cu}$ alloys. The nucleation rate of F-ICO clusters was increased with $\mathrm{Cu}$ 
content. It contributed to increasing stability of undercooling melt and GFA of $\mathrm{Zr}-\mathrm{Cu}$ alloy; On the other hand, the chemical composition leaded to the evolution of chemical short range ordering. The change of chemical short range ordering provided crystal nucleation driving force. Base on above two pointes, reduced fraction of F-ICO, $B_{\mathrm{c}}$, was proposed to establish the relation of structure-composition-GFA for $\mathrm{Zr}-\mathrm{Cu}$ binary alloys. Peaks in $B_{\mathrm{c}}$ over broad compositional ranges were clearly observed. These peaks were in good agreement with GFA. In summary, $B_{\mathrm{c}}$ could correctly indicate GFA over a broad compositional rang in the $\mathrm{Zr}-\mathrm{Cu}$ binary alloy system.

\section{References}

1. W.H. Wang, C. Dong, C. H, Bulk metallic glasses, Mater. Sci. Eng. R.. 44 (2004) 45-89.

2. A. R. Yavari, J. J. Lewandowski, J. Eckert, Mechanical properties of bulk metallic glasses, MRS Bul. 32 (2007)635-638.

3. Inoue A, Shen BL, Koshiba H, et.al, Cobalt-based bulk glassy alloy with ultrahigh strength and soft magnetic properties, Nature Materials. 18 (2003)661-663.

4. H. Kato, H.S. Chen, and A Inoue, Relationship between thermal expansion coefficient and glass transition temperature in metallic glasses, Scr. Mater. 58 (2008)1106-1109.

5. E.S. Park , D.H. Kim, Correlation between volumetric change and glass-forming ability of metallic glass-forming alloys, Appl. Phys. Lett. 92(2008) 091915.

6. D. Wang, Y. Li, B.B. Sun and E.Ma, Bulk metallic glass formation in the binary $\mathrm{Cu}-\mathrm{Zr}$ system, Appl. Phys. Lett. 84(2004) 4029.

7. M.B. Tang, D.Q. Zhao and W.H. Wang. Chin.Phys.Lett.21(2004) 901.

8. F.C. Frank 1952 Proc. R. Soc. London, Ser. A 21543.

9. H. Jonsson and H.C. Andersen, Icosahedral Ordering in the Lennard-Jones Liquid and Glass, Phys. Rev. Lett. 60 (1988)2295-2298.

10. Y.T. Shen, T.H. Kim and K.F. Kelton, Icosahedral Order, Frustration, and the Glass Transition: Evidence from Time-Dependent Nucleation and Supercooled Liquid Structure Studies, Phys.Rev.Lett.102(2009) 057801.

11. Z.D. Sha, Y.P. Feng and Y. Li, Statistical composition-structure-property correlation and glass-forming ability based on the full icosahedra in $\mathrm{Cu}-\mathrm{Zr}$ metallic glasses, Appl. Phys. Lett. 96(2010) 061903.

12. H.L. Peng, M.Z. Li, W.H. Wang et al., Effect of local structures and atomic packing on glass forming ability in CuxZr100- x metallic glasses, Appl.Phys.Lett.96(2010) 021901 .

13. J.C. Lee, K.W. Park, K.H. Kim et al., Origin of the plasticity in bulk amorphous alloys, J. Mater. Res 22 (2007)3087-3097.

14. DeBoer F R, Boom R, Mattens W C M et al. 1989 Cohesion in Metals. North-Holland, Netherlands. 1-297:335-338. 